\title{
Bed morphology changes at river contractions
}

\author{
G. Oliveto \& M.C. Marino \\ University of Basilicata, School of Engineering, Potenza, Italy
}

\begin{abstract}
Contraction scour is a significant problem of engineering concern which might occur when the stream encounters a reduction in flow area because of either natural constraints or hydraulic works. This paper is a part of ongoing investigations by the authors on the spatial and temporal variations in bed morphology at both short and long river contractions based on experimental investigations at laboratory scale. Experiments were carried out at University of Basilicata, Italy, in a $1 \mathrm{~m}$ wide and $20 \mathrm{~m}$ long rectangular channel. The working section was up to $16 \mathrm{~m}$, depending on the length of the contraction model. Two nearly-uniform sediments were used as mobile bed, sand with median grain size $d_{50}=1.7 \mathrm{~mm}$ and gravel with $d_{50}=9.0 \mathrm{~mm}$. The contraction length was either $0.5,1.0,2.0$ or $3.0 \mathrm{~m}$. Runs were carried out under steady flow and clear-water approach flow conditions. Typically they were of long duration (up to 15 days) to achieve conditions of dynamic equilibrium. New results on the effects of contraction ratio, densimetric Froude number, and relative contraction length are given. Moreover, insights on the spatial and temporal changes in bed morphology are provided with emphasis on the thalweg profile at contracted sections and bed degradation processes downstream of the contracted area.
\end{abstract}

\section{INTRODUCTION}

River contractions often occur as a result of either natural constraints (e.g. landslides, debris accumulations, longitudinal bars, confluences, etc.) or man-made structures (e.g. bridge embankments, lateral banks, spur dikes, etc.). In case of subcritical flows, the velocity increases through the contraction and scouring processes and bed degradation can develop.

Channel contractions are considered long when the flow is nearly uniform in both the undisturbed channel and the contracted reach. According to Komura (1966) this occurs when the ratio of the contraction length, $l$, to the approaching channel width, $B$, is greater than 1 , whereas greater than 2 according to Webby (1984). Dey \& Raikar (2005) substantiate the condition $l / B \geq 1$ through an extensive experimental investigation.

Straub (1934) was probably the first to suggest a simplified one-dimensional approach for long contractions from DuBoys' transport formula and Manning's equation. Many equations have been suggested afterwards, most of which were derived from Straub's approach (e.g. Laursen 1960, Komura 1966, Gill 1981, Lim \& Cheng 1998). A review of relevant literature is provided by Melville \& Coleman (2000). More recently Briaud et al. (2005) addressed the case of clear-water contraction scour in fine-grained soils. The method they suggested introduces the time effect. However, the drawback is that it requires soil testing. Dey \& Raikar (2005) considered long contractions with uniform and non-uniform sediments. They made available the experimental data for 131 runs under clear-water scour. Brandimarte et al. (2006) proposed a probabilistic approach for predicting contraction scour under unsteady flow and clearwater conditions, which accounts for the cohesion of bed material.

Compared to experimental studies there are fewer field investigations. As examples, Benedict (2003) measured clear-water contraction scour in the South Carolina Piedmont. Mueller and Wagner (2005) conducted an analysis of the available field data for contraction scour. They compared field data with estimates from the formulas of Straub, Laursen, and Komura. The results revealed overprediction in most cases, but instances of underprediction also occurred. Detailed real-time measurements of flow velocities and bed elevations for a flood in 1997 on the Pomme de Terre River in Minnesota are also provided.

However, the available experimental data to support current predictive models are still limited. Also, the majority of studies focuses only on the maximum scour depth lacking a more detailed characterization 
of bed morphology. Based on experiments at laboratory scale, this paper aims to provide some insights on the spatial and temporal evolution of bed morphology with emphasis on the effects of contraction length and the morphological characteristics of the thalweg line that typically develops along the channel axis.

\section{EXPERIMENTS}

Experiments were carried out at University of Basilicata, Italy, in a $1 \mathrm{~m}$ wide and $20 \mathrm{~m}$ long rectangular channel. In total 22 runs were performed.

The working section was up to $16 \mathrm{~m}$ long depending on the contraction model length. Two bed materials were tested, a nearly-uniform sand with median grain size $d_{50}=1.7 \mathrm{~mm}$, sediment gradation $\sigma=$ $\left(d_{84} / d_{16}\right)=1.5$, and dimensionless grain size $D_{*}=$ $\left(\mathrm{g}^{\prime} / v^{2}\right)^{1 / 3} d_{50}=43$ and a nearly-uniform gravel with $d_{50}=9.0 \mathrm{~mm}, \sigma=1.5$, and $D_{*}=228 . v$ is the kinematic viscosity of water and $\mathrm{g}^{\prime}$ is equal to $\mathrm{g}\left(\rho_{s}-\rho\right) / \rho$ with $\rho$ $=$ mass density of water, $\rho_{s}=$ mass density of sediment, and g gravitational acceleration. Sand was used to simulate transition conditions in the field at the interface sediment-water and gravel hydraulically rough conditions, according to the Shields' diagram.

The contraction model was made of three parts. The middle one was straight-lined and either 0.5 , $1.0,2.0$, or $3.0 \mathrm{~m}$ long, the entrance and outlet parts were almost streamlined to minimize energy losses and local scour effects. Three contraction ratios $\beta=$ $b / B=0.9,0.8$, and 0.7 were tested with $b$ the width of the contracted reach (in its middle part) and $B$ the width of the uncontracted approach channel. The upstream end of the contraction model was located about $9 \mathrm{~m}$ from the channel inlet to allow a fully developed turbulent flow at the contraction entrance.

All the experiments were conducted under initial plane bed, steady flow, and clear-water approach flow conditions. The discharges were measured, to an accuracy of $\pm 3 \%$, by an orifice plate installed in the circuit. The water surface was read by a conventional point gauge with accuracy to the nearest millimetre and the sediment surface was read, to an accuracy of the order of the grain size, by a shoe gauge having a $4 \mathrm{~mm}$ by $2 \mathrm{~mm}$ wide horizontal plate at its base. At the end of each run detailed measurements of the bed topography (around 500 bed-level data) were made, while only some measurements along the longitudinal channel axis were taken during the run to minimize disturbances to the flow dynamics.

The approach flow depth, $h$, was controlled by an adjustable sharp-crested weir at the end of the channel. Once the bed was carefully levelled, the channel was slowly filled to inhibit any sediment movement by submerging the working section with the weir. The water discharge was then slowly increased to the preselected value and the experiment started when the approach flow depth was set to the preselected value by lowering the weir.

Figure 1 shows the free surface and the observed bed morphology at the end of the run 21 with sandy bed, contraction ratio $\beta=0.7$, and contraction length $l=3.00 \mathrm{~m}$.
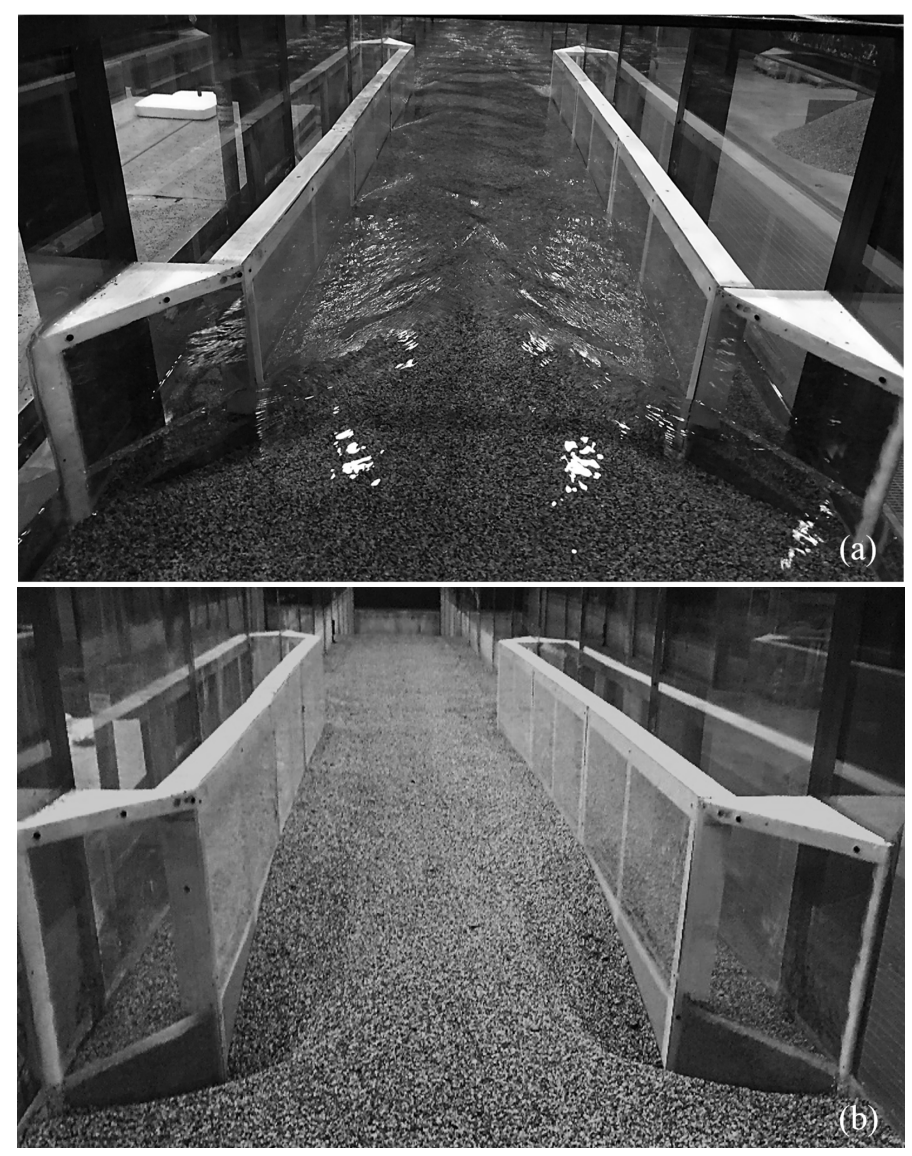

Figure 1. Run 21 with discharge $Q=0.040 \mathrm{~m}^{3} / \mathrm{s}$ and approach flow depth $h=0.10 \mathrm{~m}$. (a) Free surface during the run, (b) Bed morphology at the end of the run.

Main conditions and results for runs from 1 to 19 are provided in Oliveto \& Marino (2015). Here Tables 1 and 2 give the main characteristics for the new runs 20, 21, and 22 with $\mathrm{R}=$ Reynolds number, $\mathrm{F}=$ Froude number, $\mathrm{F}_{d}=V /\left(\mathrm{g}^{\prime} d_{50}\right)^{1 / 2}$ densimetric Froude number with $V$ cross sectional flow velocity, $\mathrm{F}_{d i}=$ inception densimetric Froude number as defined by Hager and Oliveto (2002), $\zeta=$ maximum scour depth, $\chi=$ longitudinal distance of $\zeta$ from the upstream end of the contraction model, $\lambda=$ scour hole length, and $t=$ time from run starting. $\mathrm{R}, \mathrm{F}, \mathrm{F}_{d}$, and $\mathbf{F}_{d i}$ refer to the approach channel while the characteristics of bed morphology are observed at the channel axis. The middle part length of the contraction model (hereafter called contraction length $l$ ) was $3.0 \mathrm{~m}$, $\beta=0.7$, and the bed was made of sand.

Table 1. Main test conditions for the new runs 20, 21, and 22. $t_{e}$ is the run duration.

\begin{tabular}{cccccc}
\hline Run & $\mathrm{R} \cdot 10^{-3}[-]$ & $\mathrm{F}[-]$ & $\mathrm{F}_{d}[-]$ & $\mathrm{F}_{d i}[-]$ & $t_{e}[\mathrm{~h}]$ \\
\hline 20 & 133 & 0.40 & 2.41 & 3.24 & 8.0 \\
21 & 133 & 0.40 & 2.41 & 3.24 & 1.0 \\
22 & 185 & 0.33 & 2.41 & 3.42 & 21.0 \\
\hline
\end{tabular}


Table 2. Main results for the new runs 20, 21, and 22. $t$ is the time from run starting.

\begin{tabular}{ccccc}
\hline Run & $\zeta[\mathrm{m}]$ & $\chi[\mathrm{m}]$ & $\lambda[\mathrm{m}]$ & $t[\mathrm{~h}]$ \\
\hline 20 & 0.079 & 1.45 & 4.23 & 8.0 \\
21 & 0.079 & 1.09 & 4.23 & 1.0 \\
22 & 0.055 & 1.55 & 4.56 & 1.0 \\
& 0.091 & 1.11 & 4.61 & 21.0 \\
\hline
\end{tabular}

\section{BASIC OBSERVATIONS}

As above said, in this study emphasis was given on the different behaviour between long and short contractions and, more in general, on the effects of the contraction length.

Figure 2 shows the bed morphology at the end of runs 16,14 , and 20 with same hydraulic and sediment conditions $\left(Q=0.040 \mathrm{~m}^{3} / \mathrm{s}, h=0.10 \mathrm{~m}, d_{50}=1.7\right.$ $\mathrm{mm}$ ) same run duration ( $t_{e}=8$ hours), but different contraction length $l$ equal to $0.5,2.0$, and $3.0 \mathrm{~m}$, respectively.

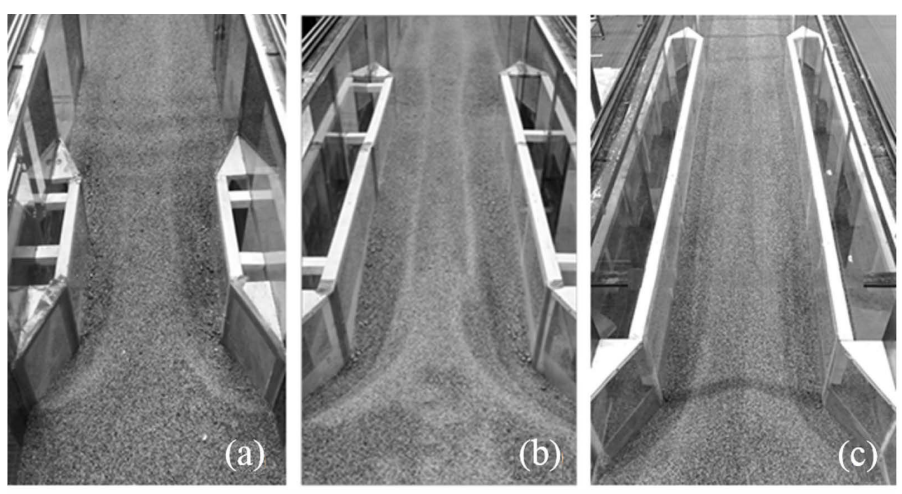

Figure 2. Observed bed morphologies at the end of runs 16, 14, and 20 (view from upstream) with $\beta=0.7$, discharge $Q=401 / \mathrm{s}$, $h=0.10 \mathrm{~m}$, and test duration $t_{e}=8 \mathrm{~h}$, but different contraction length $l$ equal to: (a) 0.5 , (b) 2.0 , and (c) $3.0 \mathrm{~m}$, respectively.

With reference to the same runs, Figure 3 shows the longitudinal bed profiles along the transects at $y=0.2$ and $0.5 \mathrm{~m}$, with $y$ distance from the right wall (relative to a view downstream).

The comparison among the longitudinal axial profiles (hereafter called thalweg lines) reveals that the maximum thalweg depth increases as contraction length increases. However, this outcome has not received much attention so far. Also the magnitude of scour holes at the contraction inlet appears increasing as the contraction length increases. This effect could be explained by the mutual interaction between local and contraction scour phenomena. In other words, bed degradation intensifies as contraction length increases making easier the progress of scour holes at the contraction inlet. A single thalweg line typically develops along the channel axis. It extends significantly downstream of the contracted region in case of short contraction (almost six times the contraction length $l$ for run 16). While it mainly develops in the contracted region for runs 14 and 20 .

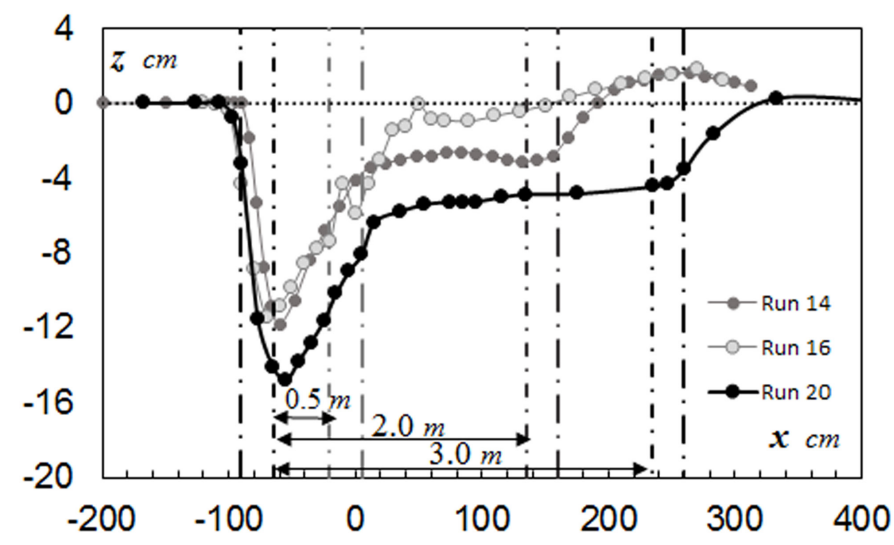

(a)

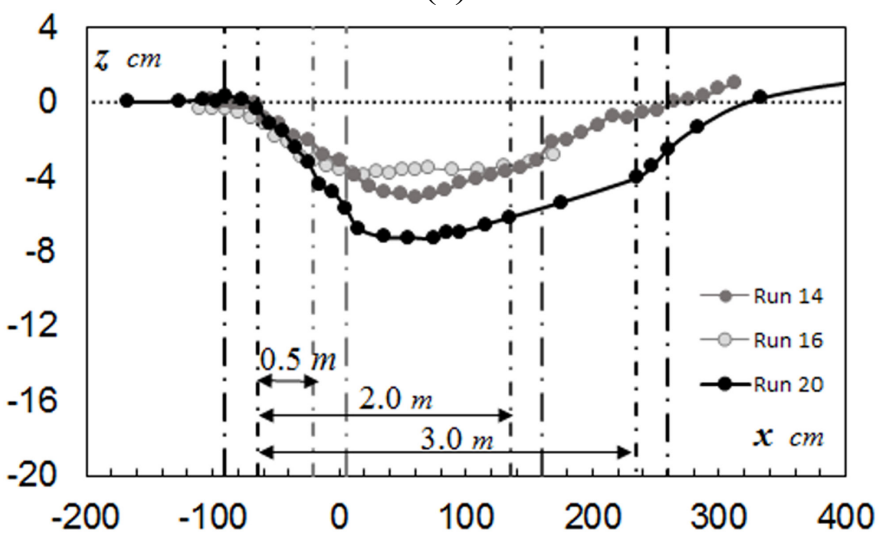

(b)

Figure 3. Comparison between observed bed profiles for run 16 (•) with $l=0.5 \mathrm{~m}$, run $14(\bullet)$ with $l=2.0 \mathrm{~m}$, and run $20(\bullet)$ with $l=3.0 \mathrm{~m}$. (a) Longitudinal bed profile along the transect at $y=0.2$ and (b) $y=0.5 \mathrm{~m}$.

Figure 4 shows some cross-sectional bed shapes still for the same runs. The section $A-A^{\prime}$ is located at the beginning of the inlet reach and $\mathrm{B}^{-\mathrm{B}^{\prime}}$ at the end of the inlet reach in the flow direction. The bed profiles at sections $\mathrm{A}-\mathrm{A}^{\prime}$ and $\mathrm{B}-\mathrm{B}^{\prime}$ confirm that the scour hole magnitude increases as the contraction length increases while the bed level at the channel axis remains at its original value. Then, it appears that contraction scour effects are negligible or even absent at the contraction inlet. When looking at the section $\mathrm{C}$ $\mathrm{C}^{\prime}$ (Figure 5) it can be noted a transversely uniform bed degradation for long contractions (runs 14 and 20 ), while a significant overlapping between local and contraction scour phenomena occur for short contractions (run 16) with a dominance of the former phenomenon over the latter. Some deposition at the lateral walls would occur at the section D-D' independent of the contraction length. These lateral deposition regions extend longitudinally for a significant length (almost twice the contraction length) in case of short contraction. Conversely, they are of limited magnitude in case of long contractions where sediment deposit occurs rather at the central region of the channel. This is almost evident in case of run 20 in which the longer contracted reach would allow the development of a nearly-uniform kinematic field with a correspondent uniform bed degradation and an almost uniformly extended depositional region. 


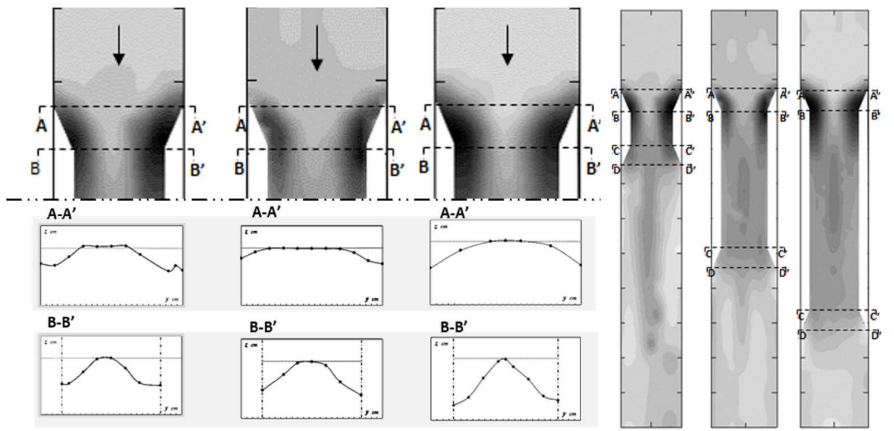

Figure 4. Cross-sectional bed shapes at contraction inlet for (from left to right) runs 16, 14, and 20. The horizontal line represents the undisturbed bed level.

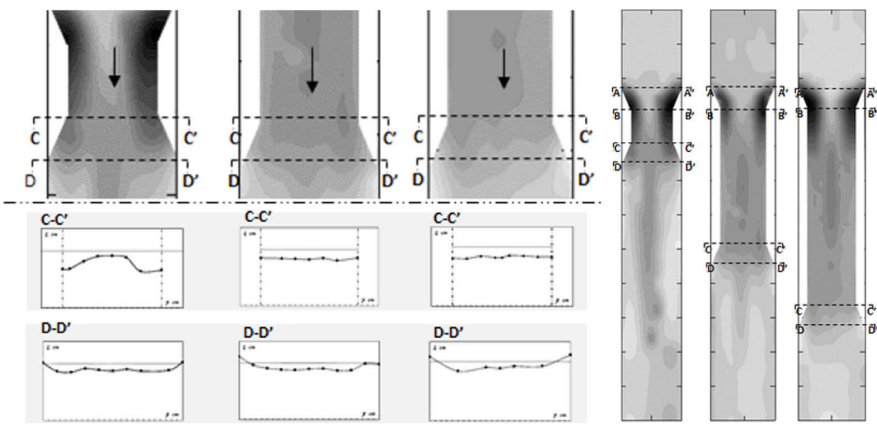

Figure 5. Cross-sectional bed shapes at contraction outlet for (from left to right) runs 16, 14, and 20. The horizontal line represents the undisturbed bed level.

Plots in Figure 6 further support the above considerations. They compare longitudinal bed profiles for runs 20 and 21 with different duration $(8$ and $1 \mathrm{~h}$, respectively) but same hydraulic and sediment conditions $\left(Q=0.040 \mathrm{~m}^{3} / \mathrm{s}, h=0.10 \mathrm{~m}, d_{50}=1.7 \mathrm{~mm}\right)$. The transects $\mathrm{A}-\mathrm{A}^{\prime}$ at $y=0.5 \mathrm{~m}$ and $\mathrm{B}-\mathrm{B}^{\prime}$ at $y=0.2 \mathrm{~m}$ are also considered. Scour depths are deeper for run 20 compared to run 21 , as expected. The deposit region downstream of the contraction model and along the axis remains practically unchanged over the time while it tends to vanish over the time along the lateral wall.

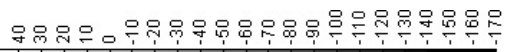
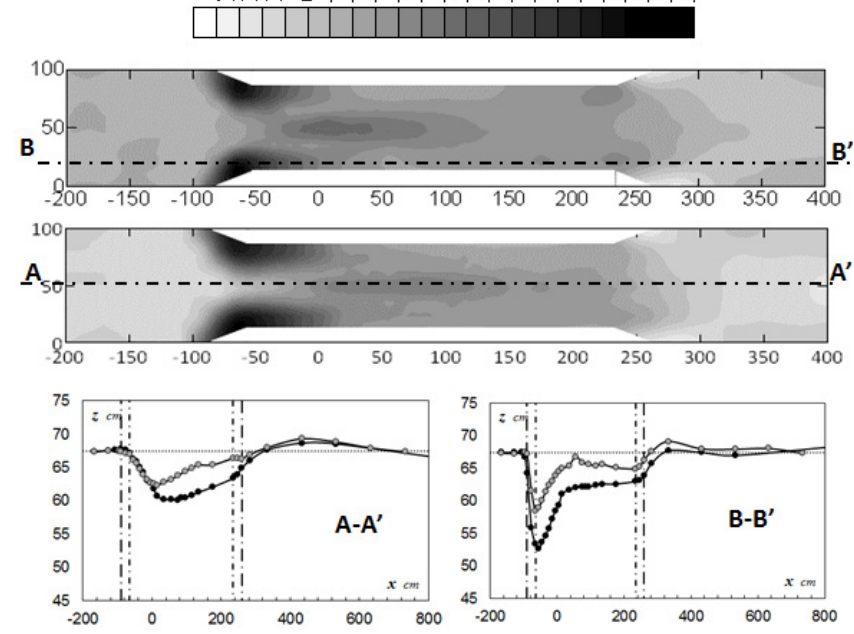

Figure 6. Comparison of bed morphology at the end of runs 20 and 21 . The upper contour plot refers to run 21 , the lower to run 20. Diagrams in the lower part of the figure compare the bed profiles along the transects at $y=0.5\left(\mathrm{~A}-\mathrm{A}^{\prime}\right)$ and $y=0.2 \mathrm{~m}$ $\left(\mathrm{B}-\mathrm{B}^{\prime}\right)$ with $(\bullet)$ for run 20 and $(\bullet)$ for run 21 . Bed elevations are in $\mathrm{mm}$ for contour plots and $\mathrm{cm}$ for bed profiles.

\section{MAJOR FEATURES OF THALWEG PROFILE}

Oliveto \& Marino (2015) provided power-type equations to predict the temporal progress of the main scour hole characteristics for long contractions. They also remarked the need for further experiments to better understand the effects of the contraction length. Here the equations suggested by the above authors are revised on the light of the new experiments in Tables 1 and 2 with significant contraction length of $3 \mathrm{~m}$. The analysis will be focused on the longitudinal thalweg profile that develops along the channel axis.

According to Oliveto \& Marino (2015), the maximum thalweg depth $\zeta$ at a given time $t$ can be given in functional form as

$\zeta=f\left(V, h, v, \rho, \rho_{s}, d_{50}, \sigma, B, b, l, \mathrm{~g}, t\right)$

with $V=$ approach cross-sectional flow velocity and $h=$ approach flow depth. In turbulent flow $v$ has a little influence on scour and can be neglected. The contraction ratio parameter $\beta=b / B$ can be considered to account for the combined effect of $B$ and $b$, also g, $\rho$, and $\rho_{s}$ can be grouped into $\mathrm{g}^{\prime}=\mathrm{g}\left(\rho_{s}-\rho\right) / \rho$ (Oliveto \& Hager 2002). Equation 1 then reduces to

$\zeta=f\left(V, h, d_{50}, \sigma, \beta, l, \mathrm{~g}^{\prime}, t\right)$

Assuming $h$ and $\mathrm{g}^{\prime}$ as repeated variables and by applying the Buckingham $\pi$ theorem, one has

$Z=\frac{\zeta}{h}=f\left(\frac{V}{\sqrt{\mathrm{g}^{\prime} h}}, \frac{h}{d_{50}}, \sigma, \beta, \frac{l}{h}, \sqrt{\frac{\mathrm{g}^{\prime}}{h}} t\right)$

or

$Z=\frac{\zeta}{h}=f\left(\mathrm{~F}_{d}, \frac{h}{d_{50}}, \sigma, \beta, \frac{l}{h}, T\right)$

with $\mathrm{F}_{d}=V /\left(\mathrm{g}^{\prime} d_{50}\right)^{1 / 2}$ densimetric Froude number and $T=\left(\mathrm{g}^{\prime} d_{50}\right)^{0.5} t / h$ dimensionless time. An analogous relationships can be obtained for the length $\lambda$ of the thalweg profile.

The experimental data collected at University of Basilicata were used for regression analysis which yields the following equations

$$
\begin{aligned}
& Z=\frac{\zeta}{h}=0.06\left(\frac{h}{d_{50}}\right)^{-0.35}\left(\frac{l}{h}\right)^{0.50}\left(\frac{1-\beta}{\beta}\right)^{1.50} \mathrm{~F}_{d}^{2.0} T^{0.15} \\
& \Lambda=\frac{\lambda}{h}=1.0\left(\frac{h}{d_{50}}\right)^{-0.35}\left(\frac{l}{h}\right)^{0.75}\left(\frac{1-\beta}{\beta}\right)^{-0.15} \mathrm{~F}_{d}^{2.0} T^{0.10}
\end{aligned}
$$

with coefficient of determination $r^{2}=0.70$ and 0.87 between observed and computed values of $Z$ and $\Lambda$, respectively. Equation 5 is consistent with the condition that $Z$ is equal to zero when $\beta=1$ and go to infinity as $\beta \rightarrow 0$. Moreover, $\Lambda$ is only slightly dependent on contraction ratio $\beta$. Equation 5 differs from the 
corresponding one in Oliveto \& Marino (2015) mainly for the power of the variable $l / h$ that was statistically found lower in this study in which the range of $l / h$ has been expanded. The comparison between experimental and computed values from Equations 5 and 6 shows as data points are reasonably well distributed around the line of perfect agreement with deviations generally within $\pm 30 \%$ (Figures 7 and 8). The t-test analysis of data showed that the most significant variables in order of importance are $\beta, \mathrm{F}_{d}, T, h / d_{50}$, and $l / h$ in case of $Z$ while $\Lambda$ is mainly function of $l / h$ and $F_{d}$. Figures 7 and 8 also show data points for short contractions (i.e. $l / B<1.0$ ). Systematic overestimations for $Z$ and underestimations for $\Lambda$ can be observed. This could be due to the fact that, in case of short contractions, the combined effects of local and contraction scour processes are considerable also at the channel axis, as also commented in the previous section.

The length of the thalweg profile can also be normalized to the contraction length $l$. In this case the following equation was found from dimensional and statistical analyses

$$
\Lambda^{\prime}=\frac{\lambda}{l}=1.0\left(\frac{h}{d_{50}}\right)^{-0.35}\left(\frac{l}{h}\right)^{-0.25}\left(\frac{1-\beta}{\beta}\right)^{-0.15} \mathrm{~F}_{d}^{2.0} T^{0.10}
$$

with $r^{2}=0.78$ between observed and computed values of $\Lambda^{\prime}$. Equation 7 implies that the thalweg line originated from long river contraction could extend downstream to the contraction outlet for a length up to 3 times the contraction length mainly depending on the approach densimetric Froude number $\mathrm{F}_{d}$ and the relative submergence $h / d_{50}$. Also, the thalweg line tends to be confined in the contracted region as either $l / h$ or $\beta$ increases.

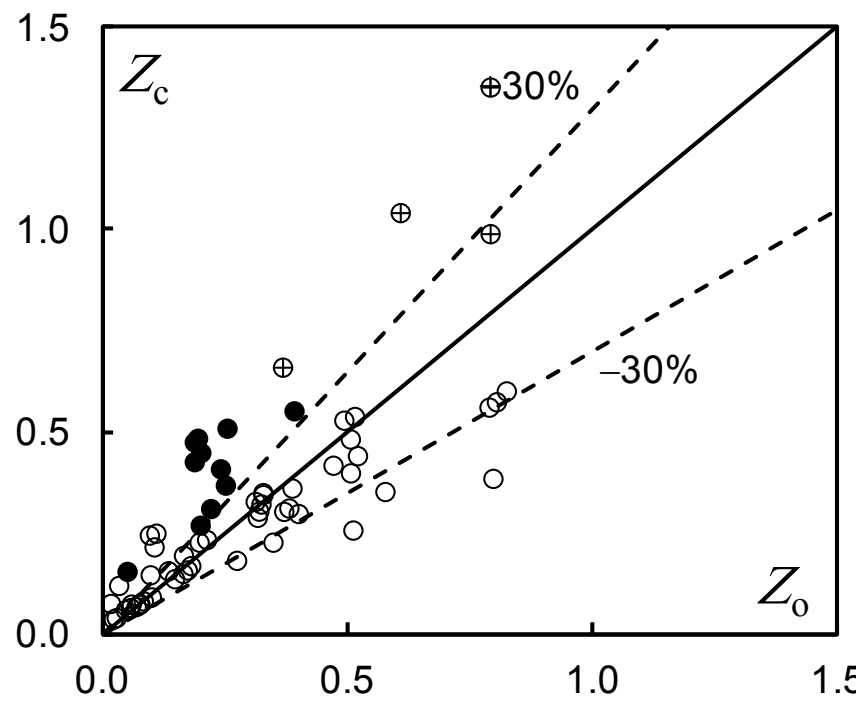

Figure 7. Comparison between observed (subscript "o") and computed (subscript "c") values of $Z$ for the experiments of this study. White symbols identify long contractions (those marked with " + " refer to the highest relative contraction length $l / B=3$ ), while black refer to short contractions.

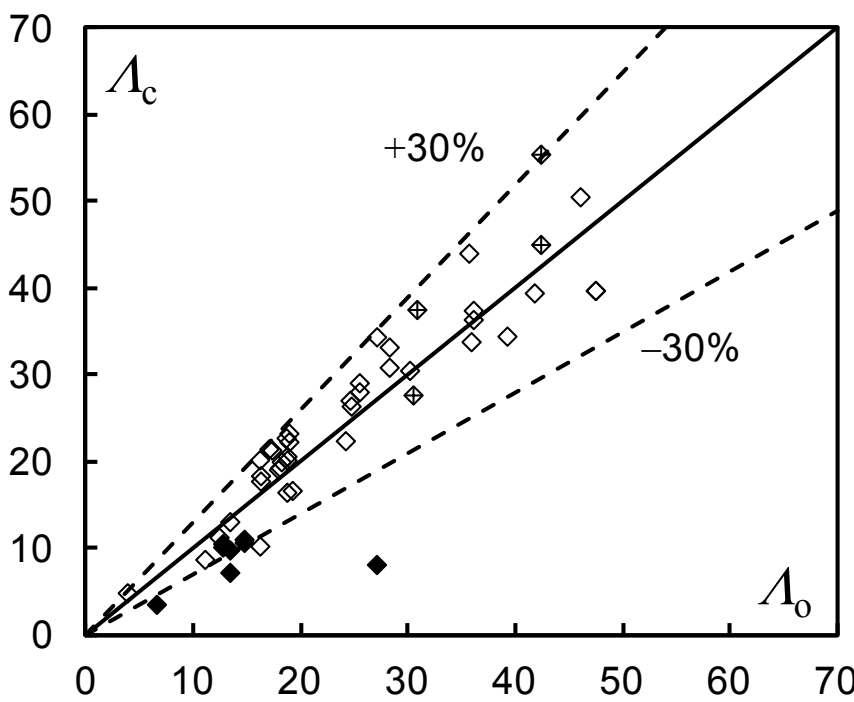

Figure 8. Comparison between observed (subscript "o") and computed (subscript "c") values of $\Lambda$ for the experiments of this study. White symbols identify long contractions (those marked with "+" refer to the highest relative contraction length $l / B=3$ ), while black refer to short contractions.

\section{CONCLUSIONS}

Laboratory experiments on bed morphology changes in river contractions were carried out at the Hydraulic Engineering Laboratory, University of Basilicata, Italy. Runs typically lasted some days to achieve well-deepen bed morphologies, but runs of short duration (few hours) were also carried out to obtain reliable experimental data at the earlier scour stages. The main results can be summarized as follows.

Experimental observations revealed that the magnitude of scour hole would increase as contraction length increases. This facet has not received much attention so far. Moreover, a single thalweg line typically develops along the channel axis and it could extend significantly downstream of the contracted region.

Power-type equations to predict the temporal progress of the longitudinal thalweg profile were suggested in terms of the governing parameters. The main dimensionless parameters governing the relative thalweg depth are, in order of importance, contraction ratio, approach densimetric Froude number $\left(\mathrm{F}_{d}\right)$, dimensionless time, relative submergence $\left(h / d_{50}\right)$ and relative length of the contracted reach $(l / h)$. The relative length of the thalweg profile is mainly dependent on $l / h$ and $\mathrm{F}_{d}$. Ranges of validity for the proposed equations are $18.81 \leq h / d_{50} \leq 88.65$, $4.94 \leq l / h \leq 30.00,0.70 \leq \beta \leq 0.90,1.08 \leq \mathrm{F}_{d} \leq 2.44$, and $1.0 \cdot 10^{3} \leq T \leq 2.1 \cdot 10^{6}$.

Further research works might concern ultimate predictive models also considering literature data, the applicability of the proposed time-dependent relationships to unsteady flow regimes, and the investigation of live-bed conditions. 


\section{REFERENCES}

Benedict, S.T. 2003. Clear-water abutment and contraction scour in the coastal plain and piedmont provinces of South Carolina, 1996-99. U.S. Geological Survey, WaterResources Investigations Report 03-4064. Columbia, South Carolina.

Brandimarte, L., D’Odorico, P. \& Montanari, A. 2006. A probabilistic approach to the analysis of contraction scour. Journal of Hydraulic Research 44(5): 654-662.

Briaud, J.-L., Chen, H.-C., Li, Y., Nurtjahyo, P. \& Wang, J. 2005. SRICOS-EFA method for contraction scour in finegrained soils. Journal of Geotechnical \& Geoenvironmental Engineering 131(10): 1283-1294.

Dey, S. \& Raikar, R.V. 2005. Scour in long contractions. Journal of Hydraulic Engineering 131(12): 1036-1049.

Gill, M.A. 1981. Bed erosion in rectangular long contraction. Journal of the Hydraulics Division 107(3): 273-284.

Hager, W.H. \& Oliveto, G. 2002. Shields' entrainment criterion in bridge hydraulics. Journal of Hydraulic Engineering 128(5): 538-542.

Komura, S. 1966. Equilibrium depth of scour in long constrictions. Journal of the Hydraulics Division 92(5): 17-37.

Laursen, E.M. 1960. Scour at bridge crossing. Journal of the Hydraulics Division 86(2): 39-54.

Lim, S.-Y. \& Cheng, N.-S. 1998. Scouring in long contractions. Journal of Irrigation and Drainage Engineering 124(5): 258-261.

Melville, B.W. \& Coleman, S.E. 2000. Bridge Scour. Highlands Ranch, Colorado: Water Resources Publications.

Mueller, D.S. \& Wagner, C.R. 2005. Field observations and evaluations of streambed scour at bridges. U.S. Geological Survey, Water Resources Divisions Report No FHWA-RD03-052. Louisville, Kentucky.

Oliveto, G. \& Hager, W.H. 2002. Temporal evolution of clearwater pier and abutment scour. Journal of Hydraulic Engineering 128(9): 811-820.

Oliveto, G. \& Marino, M.C. 2015. Experimental and numerical investigation of the bed morphology evolution in river contractions. E-Proc. $36^{\text {th }}$ IAHR World Congress, The Hague, the Netherlands, 28 June - 3 July 2015.

Straub, L.G. 1934. Effect of channel contraction works upon regime of movable bed streams. Trans. Am. Geophysical Union Part II: 454-463.

Webby, M.G. 1984. General scour at contraction. RRU Bulletin 73, National Roads Board, Bridge Design and Research Seminar, New Zealand: 109-118. 